\title{
AVALIAÇÃO PARTICIPATIVA ONLINE E OFF-LINE
}

\author{
Denise Leite \\ Maria Cecília Loréa Leite \\ Maria Elly Herz Genro \\ Marlis Morosini Polidori \\ Mônica Pagel Edelwein \\ Clarice Escott \\ Glades Félix \\ Regina Céli Machado Pires \\ Renata Silva Machado (BIC/CNPQ) \\ Marieta Reis (BIC/CNPQ). ${ }^{1}$
}

Avaliado em: 24/08/07

1 Grupo de Pesquisa Inovaval, Coordenação Denise Leite, Docente Permanente PPGEDU/UFRGS. Investigação apoiada pelo CNPq. Instituições participantes: UFRGS, PUCRS, UFPEL, IPA, ONG AFASO, UDELAR, UY. E.mail: denise.leite@ pesquisador.cnpq.br; dleite@ portoweb.com.br

Resumo: Este é um trabalho de pesquisa coletiva que vem sendo construído por várias mãos no espaço da parceria. O texto apresenta a revisão de literatura, metodologia e resultados parciais de uma investig ação que entende Avaliação Participativa (AP) em seu acoplamento com Tecnologias da Informação e da Comunicação (TICs), um tema sobre o qual as pedagogias ainda não produzem respostas suficientes e adequadas. Mostra como foram captadas (observação e mini-estudos etnográficos), registradas (protocolos e estudos de caso) e analisadas (referenciais) as formas de avaliação que foram praticadas em cenários universitários, educação presencial e não presencial, educação a distância (EAD) e em cenários de ações sociais e educação não formal, praticadas em periferias urbanas (ONG).

Palavras-chave: Avaliação participativa; TICs; Inovação; Pedagogia Universitária; Universidade.

\section{PARTICIPATIVE EVALUATION ONLINE AND OFF LINE}

Abstract: This is a collective research that has been constructed collaboratively by many hands. The text presents the literature research, the methodology and the partial results of an investigation that understands Participative Evaluation (PE) in its connection with the Information and Communication Technologies (ICTs), a topic about which the pedagogies still do not produce sufficient or adequate answers. It shows how the kinds of evaluation that were practiced in university settings, presential and distance education and; and in social action and non-formal education settings, practiced in urban peripheries (NGO) are collected (observation and mini ethnographic studies), registered (protocols and case studies) and analyzed (referentials).

Key words: Participative evaluation; Innovation; University pedagogy; University. 


\section{INTRODUÇÃO}

Este é um trabalho de pesquisa coletiva que vem sendo construído por várias mãos no espaço da parceria. O texto apresenta a revisão de literatura, metodologia e resultados parciais de uma investigação que entende Avaliação Participativa (AP) em seu acoplamento com Tecnologias da Informação e da Comunicação (TICs), um tema sobre o qual as pedagogias ainda não produzem respostas suficientes e adequadas. Mostra como foram captadas (observação e mini-estudos etnográficos), registradas (protocolos e estudos de caso) e analisadas (referenciais) as formas de avaliação que foram praticadas em cenários universitários, educação presencial e não presencial, educação a distância (EAD) e em cenários de ações sociais e educação não formal, praticadas em periferias urbanas (ONG).

Este objeto de pesquisa tem natureza pedagógica e política. Descobrir novos formatos de avaliação implica discutir as aprendizagens feitas a partir das referências de quem é o intérprete, quem detém saber, quem detém poder (es) e está controlando a distribuição de conhecimento. Entende-se que "a avaliação condensa o significado da totalidade do dispositivo pedagógico." (BERNSTEIN, 1998, p.66), e este especializa formas de consciência, controla significados (o que se pode e não se pode pensar). Desta forma, também pode abrir espaços para o impensável, uma avaliação democrática para novos incluídos.

\section{Avaliação participativa e aprendizagens: revisando a literatura em busca de aproximações}

Avaliação participativa na universidade não tem sido um tema preferencial de pesquisa. Fala-se sobre ela e critica-se o autoritarismo praticado tanto nas ações avaliativas de sala de aula quanto nas ações de avaliação institucional. Desde 1975, Boaventura de Sousa Santos critica a pedagogia que inibe resposta participativa do aluno na avaliação, ainda que o professor faça uso de modelos anti-autoritários de ensino-aprendizagem. Autores como Ludke e Salles (1997); Castro-Almeida, Boterf e Nóvoa (1993); Cousins e Earl (1995); House (2000); SAUL (2000); House e Howe (2001); Dias Sobrinho e Ristoff (2002); Diligenti (2003), dentre outros, tratam do tema AP como prática pedagógica e política no ensino superior. O tema da participação (atenuada) aparece em modelos de avaliação de Stake, Patton, Guba e Lincoln, Macdonald, Parlett e Hamilton. Alguns dentre os modelos de avaliação se caracterizam como metodologias de 
investigação-ação onde a participação se apóia em pressupostos de democracia liberal-representativa.

Neste estudo se compreende a AP baseada em princípios de democracia forte (BARBER, 1997) e emancipação social (SANTOS, 2004). Constitui um pressuposto deste estudo que uma metodologia não carrega consigo a condição plena e suficiente para caracterizar a participação política. É preciso que as ações avaliativas estejam direcionadas para autocrítica, autogestão, autolegislação e autovigilância de sujeitos sobre tais processos, com partilha horizontal de poderes e saberes. A função da participação é produzir a "educação do julgamento" (BARBER, 2004). Com isso, a AP prescinde do expert, pois, sujeitos de diferentes saberes e posições de poder produzem conhecimento com ela, sobre o que fazer, como fazer, como fiscalizar a ação. A epistemologia subjacente produz autonomias e a aprendizagem das regras do jogo democrático (LEITE, 2005).

A procura de aproximações à AP justifica-se quando se tem um campo de estudos pouco explorado e sistematizado, quando os saberes e conhecimentos existem, mas não estão totalizados e aparecem em certo grau de desordem. A avaliação sendo um modo de conhecer e aprender produz subjetivação. Nas aulas, presenciais e não presenciais, os procedimentos costumam ser ritualizados e reprodutivistas, produzidos por um dispositivo pedagógico e um discurso pedagógico que regula a ordem. Desta forma, as práticas educativas podem reproduzir modos de subjetivação individualista e possessivo através da avaliação. Nas aulas, nem sempre a avaliação contribui para formar sujeitos políticos e participativos, cidadãos da pólis. Por outro lado, em situações de ensino com as TICs a avaliação tem mostrado ser um processo de aprendizado colaborativo (Seria também participativo?) quando em situação de intercâmbio do saber-fluxo (LÉVY, 1998)² , não necessariamente do saber - institucionalizado e formal. Nesse aspecto, a aprendizagem pode atingir um grau de autonomia do sujeito frente ao saber auto-gerido que comporta o seu contrário, ou seja, o fechamento de sentidos para o coletivo. Nessas oposições, características do momento vivido em educação, situam-se as justificativas para aumentar a compreensão sobre avaliações que envolvam participação.

Por outro lado, na sociedade da informação e da comunicação, o papel do professor e do aluno na aprendizagem com o auxílio das máquinas, está constantemente mudando. $\mathrm{O}$ docente aprende junto com os alunos,

2 Saber fluxo - expressão de Pierre Lévy para designar um saber caótico, de curso dificilmente previsível oferecido pela virtualização do conhecimento no ciberespaço. 
ambos como profissionais aprenderão de forma continuada, por toda vida, online e off-line. A máquina, que substituiu o quadro negro, o giz e o livro, constitui uma, ainda nova, tecnologia para o ensino-aprendizagem. Para alguns, o computador seria a máquina de ensinar que substituiria o professor, redimensionando espaços e tempos e produzindo impactos sobre todos. Para outros, as máquinas seriam meros instrumentos para comunicação, investigação e navegação. O que muda são os paradigmas das práticas pedagógicas, as identidades e mentalidades, os modos de subjetivação dos aprendizes, a forma de transação com o conhecimento. Nesse entrevero, a formação educativa institucionalizada sofre com a falta de saberes sobre novos formatos de avaliação.

Para nosso grupo de pesquisa, uma questão sutil se delineia - para cada situação de ensino-aprendizagem, para cada ecologia cognitiva corresponde alguma avaliação e, com ela, se estabelecem distintas formas de poder. Dependendo dos atores que detêm os saberes - sobre o próprio conhecimento objeto, sobre o uso da máquina, sobre o emprego da tecnologia - deslocam-se os poderes. A avaliação capta estes poderes em sua horizontalidade (participação) e em sua verticalidade (individualização). Quem detém maior acumulação de saber, impõe regras e valores, pois é percebido como portador do domínio. Isto ocorre tanto no nível micro-institucional como o da sala de aula ou da oficina na ONG, como no nível macro-institucional, do programa de EAD ou de avaliação institucional, e, se expandirmos o olhar, na relação entre países periféricos e centrais.

Inicialmente as pesquisas do grupo InovAval tiveram a avaliação de instituições como objeto. Nelas se procuravam as práticas que envolvessem participação e co-gestão. No Brasil, e desde Porto Alegre especialmente, falar em participação era tema comum. Ela ocorre em várias esferas de atuação pública. Uma das mais conhecidas experiências denominase Orçamento Participativo das Cidades, hoje de domínio internacional.

Especificamente, sobre avaliação participativa na universidade, encontra-se um número reduzido ou pouco divulgado de ações ou autorias sobre o tema. Em 1975, Santos publicou um texto sobre a democratização da universidade e discutiu os "Sete fôlegos da pedagogia repressiva", dizendo que a inovação pedagógica pode passar uma mensagem de facilidade aos alunos; que a pedagogia repressiva da educação fundamental à terciária, condiciona a resposta participativa dos alunos. Na constatação de Boaventura Santos, o professor usa um modelo anti-autoritário no processo ensino-aprendizagem e um modelo autoritário no processo de avalia- 
ção. Outros autores trataram do tema no ensino superior e profissionalizante. Alguns o abordam de forma geral. Outros, como Diligenti (2003), por exemplo, descrevem uma experiência de investigação participante em aulas de Geometria, sugerindo uma alternativa possível e transformadora da própria avaliação. Já Saul $(2000 ; 2001)$ aborda a participação em processos de avaliação emancipatória para projetos sociais e para reformulação de currículos. Enquanto Dias Sobrinho e Ristoff (2002) abordam o tema de forma constante em suas publicações, caracterizando procedimentos democráticos de avaliação institucional das universidades. Para Santos (2004) a universidade reformada, do século XXI, precisa armar uma estrutura em rede com democracia interna e avaliação participativa.

Se acionarmos um sistema de procuras na WorldWideWeb vamos encontrar inúmeras referências à avaliação participativa. Nessa fonte, são raros os relatos de investigações sobre o tema. Em geral, os formatos denominados avaliação participativa que aí aparecem, quando apresentam um referencial, este se apóia em metodologias de investigação-ação. As práticas de participação são operadas em destinos tão diferentes quanto o meio rural, desenvolvimento sustentável, consultorias profissionais a empresas, gestão de projetos sociais, trabalhos sociais de combate à pobreza, atividades do Banco Mundial, da Organização Internacional do Trabalho e outros. Dentre as muitas abordagens participativas encontram-se ações, dentro de projetos financiados pelo Banco Mundial, como, por exemplo, o Participatory Rural Appraisal - PRA 3 (1980) e o Policy Analysis for Participatory Poverty Alleviation - PAPPA. A abordagem PRA, como consta na página web, aqui citada em nota de rodapé, foi criada por Robert Chambers e Gordon Conway do International Institute for Environment and Development. A abordagem PRA defende que as comunidades não devem esperar somente pela ajuda externa para resolver seus problemas, devem participar "inaugurando" desta forma uma nova maneira para "resolver" o problema da pobreza!...

Destaca-se, então, que a palavra participação tem sido apropriada para os mais diversos fins. Seu uso pode ser uma dissimulação, uma imposição de poderes e saberes, cujas forças pendem para o lado dos mais fortes na sociedade, ou daqueles que estão em cargos de exercício de poder mandatado. Há um arremedo de situações, de tal sorte mal articuladas, que se pode dizer, constituem uma tirania da participação. Entende-se, neste caso,

3 Informação captada em 18 de abril de 2003 no endereço: http://www.clarku.edu/departments/ idce/research/ccbd/ 
a tirania como uso do poder com o objetivo de atingir determinados fins através da participação, como o situam Cooke e Kothari (2001). São formas de participação induzidas, impostas, às vezes, por um consultor, de fora para dentro das instituições, de cima para baixo. As exigências da participação, através de atividades ou ações enfeixadas sob esta denominação por agências do capitalismo hegemônico, pouco têm a ver com formas de democracia direta. São isto sim, formas de democracia de baixa intensidade.

Na literatura acadêmica, encontram-se referências à avaliação com o emprego de Novas TICs, avaliação em EAD e a avaliação cooperativa como possibilidades das TCIs. Hack, Geller e Tarouco [s/d] discutem a avaliação em EAD na visão tradicional e na progressista. Analisam e comparam seis sistemas de aprendizagem disponíveis online, na Web, e mostram como cada um aborda a avaliação, suas vantagens e desvantagens. Peters (2001) em Didática do ensino a Distância, descreve vários modelos de ensinoaprendizagem de instituições conhecidas, descrevendo as modalidades de avaliação solicitadas aos alunos. Em texto da Unesco, Visão e ação - Universidade século XXI de 1998, se faz referência às NTCIs e à mudança de paradigmas de avaliação. Examinam-se diferentes programas virtuais de universidades e afirma-se que os conceitos tradicionais de verificação de resultados serão substituídos pela avaliação de processo. A Associação de Universidades Européias lançou em maio de 2000 o documento CRE 5, onde sugere avaliação formativa como uma estratégia para avaliar o emprego das NTCIs nas universidades. Silva e Santos (2006) coordenaram livro sobre avaliação da aprendizagem online e em EAD no qual sugerem várias possibilidades para avaliação, nem todas participativas.

Quando mencionamos educação aberta ou à distância ou as tecnologias digitais aplicadas à educação estamos frente a um grande contingente de estudantes (e docentes) desejosos de inclusão. Este mundo, ainda novo, produz temores em algumas pessoas enquanto se consuma como algo familiar para outros, provenientes dos mais diferentes segmentos sociais, acostumados ao exercício das lan-houses e educados pela televisão e outros meios eletrônicos.

No Brasil a EAD constitui um recurso importante para superar a brecha tecnológica, para suplantar também, a brecha educativa daqueles que não têm acesso à escola e à universidade. Os recentes desenvolvimentos das TICs conectam a escola com o mundo globalizado (AXT, 2004). Em nosso país este é um desafio duplo: suplantar ao mesmo tempo um problema pós-moderno da educação virtual e um pré-moderno, do acesso à edu- 
cação, ao mesmo tempo. Nesse cenário, os estudantes potenciais-virtuais, que estão em diferentes pontos do país, podem ser acessados tanto por universidades tradicionais quanto por universidades-empresa nacionais ou internacionais. As Universidades Globais estão ativas em busca de alunos. O Brasil e toda América Latina são territórios de uma expansão preferencial, um grande mercado a ser atingido através da EAD! $!^{5}$ Nesse mesmo cenário, convivem exemplares projetos de formação com EAD, como aqueles coordenados pela SEED/MEC através de programas como o PROINFO e sistemas como a $\mathrm{UAB}^{4}$ que ativam parcerias entre governos federal, estadual, municipal e universidades.

Nos processos educativos empreendidos a distância ou em colaboração, ou em atividades educativas com o apoio em tecnologias da comunicação e da informação, alguns autores, como Landow (1992) e Sílvio (2000), entendem que os alunos devem subir degraus, ou andaimes de uma obra em construção, de forma lenta e gradual, dominando novas linguagens passo a passo. Nesses processos os estudantes podem assumir papéis pró-ativos, ativos ou passivos. Espera-se que possam ser protagonistas de sua própria educação, heróis cibernéticos ou pilotos de suas próprias aprendizagens (Homo sapiens ciberneticus). Espera-se que adquiram a linguagem digital, dominem os códigos lingüísticos de diferentes disciplinas e campos de aplicação mediante instruções simples e claras. Espera-se que possam responder às questões formuladas por seus professores ou tutores e realizem as provas de avaliação no tempo devido, comprovando suas aprendizagens. Para outros, como AXT e Maraschin (1999), o aluno está diante do caos, ou de um alto grau de desorganização inicial, enfrentando um novo dispositivo com tarefas mais criativas, linhas de fissura e ruptura que brotam como rizomas no cotidiano (AXT, 2004).

Temos, pois, no nível micro-institucional, um campo de saberes - o da avaliação educacional ou $d a$ aprendizagem, agindo em sinergia com outro campo - o das novas tecnologias informacionais, as quais, como reconhecemos, estão redirecionando as funções de cognição e de interação. São fundamentais nesse campo: a memória de curto prazo, a percepção, o raciocínio voltado aos códigos, com as relações e nexos, com a intuição, a imaginação e a simulação (inteligência coletiva). Para além de aprender os conteúdos da escola tradicional, o suporte tecnológico exige novas ha-

4 SEED/MEC - Secretaria de Educação a Distância do Ministério da Educação; PROINFO - Programa Nacional de Informática na Educação (Na UFRGS realizou-se o MEAD/UFRGS - Curso de Mestrado em Educação a Distância, com ênfase em Tecnologias Digitais para Educação Básica); Sistema Universidade Aberta do Brasil (Na UFRGS está em realização o PEAD/UFRGS, Curso de Licenciatura em Pedagogia). 
bilidades. É preciso trabalhar com bancos de dados, hipertextos, realidades virtuais, softwares com interfaces nem sempre amigáveis e com interconexões em tempo real. Para além destas possibilidades que compreendem novas habilidades, há uma comunicação partilhada que exige interações entre sujeitos, tão próximas que chegam a produzir sensações quase corporais. É preciso reconfigurar as tarefas e os métodos de avaliação (LANDOW, 1992). À pedagogia compete entender e interpretar, no sentido crítico, os novos dispositivos, as aprendizagens personalizadas ou aquelas ditas colaborativas. Cabe à ela colocar em campo novas propostas de avaliação. Propostas que dêem conta de que tempo, lugar, e território não possuem mais a mesma importância que tiveram em décadas e séculos anteriores.

Se a avaliação condensa o significado da totalidade do dispositivo pedagógico (Bernstein, 1998), ela vai apontar qual o conhecimento que é válido, então, avaliar é tarefa de todos. Afinal, ela vai legitimar conhecimentos e competências, capital cultural do mundo global. Contudo, como adverte Litwin (2001), a avaliação em projetos de EAD, por exemplo, não deve ser invasiva nem permanente, pois cortaria o fluxo de aprendizagens. "Isto seria desvirtuar o sentido do conhecimento" (LITWIN, 2001, p. 68). Para Lévy (1998, p. 2) é preciso reconhecer o sentido do aprendido, reconhecer as competências dos sujeitos, mesmo os saberes não acadêmicos. "Esta seria uma nova economia do conhecimento". Nesse sentido os critérios e os formatos de avaliação ainda são um inédito viável!

Por outro lado, no nível macro-institucional, temos um campo de saberes - o da avaliação institucional, bastante desenvolvido na atualidade, que acompanha e valida as iniciativas de formação da educação superior. Mas, no Brasil se observa que a avaliação institucional dos cursos de graduação vem se transformando rapidamente nos últimos dez anos e, apenas mais recentemente foram legisladas as normas e praticados os consensos sobre os melhores formatos (SINAES, ENADE). As grandes universidades, públicas e privadas, estão investindo em novas tecnologias. Aparentemente o custo-aluno do ensino assistido por computador, televisão educativa, multimídia interativa, a distância e outras modalidades, tornase menor. De certa maneira este fenômeno vem ao encontro dos interesses individuais de tempo e custo financeiro e de deslocamento dos alunos. Vem ao encontro do ensino de massas, ao tamanho do país. Contudo, a diversidade do sistema educativo e as dimensões do Brasil, tornam esta verdade relativa. Isto porque as IES privadas e as Universidades Globais internacionais têm buscado cobrar mensalidades com preços "acessíveis", 
em seus cursos. Nas universidades públicas os cursos podem ter custos elevados porque demandam equipamento e suporte sofisticado, muitas vezes, importado e oneroso. Dessa maneira, ensino presencial conjugado com ensino não presencial parece ser uma fórmula adequada. Um e outro exigem conhecimento de avaliação de projetos e de avaliação de impactos. Para Litwin (2001) trata-se de avaliar os chamados "núcleos problemáticos" dos projetos, envolvendo atores, inclusive governos, e interesses das instituições proponentes das modalidades.

\section{Avaliação participativa e seus princípios}

Em resumo, a revisão da literatura pertinente aponta para uma compreensão de avaliação participativa como uma forma predominante de investigação-ação, portanto, apoiada em uma metodologia de pesquisa. Por outro lado, não se encontraram referências à avaliação participativa apoiada em princípios de democracia forte e vinculada ao uso de novas tecnologias em educação. Este estudo reforçou o entendimento da avaliação participativa sob a égide de democracia forte e das teorias de emancipação social. Ou seja, em nossa comprensão a metodologia é importante, mas não faz a condição plena e suficiente para caracterizar a existência da participação. É preciso que a ação avaliativa esteja direcionada por princípios políticos de auto-direção, auto-legislação e auto-vigilância para que ocorra participação com partilha horizontal de poderes e saberes, para além da simples auto-crítica. Em nosso entender uma avaliação é participativa se e quando sua prática faz aproximações à vivência de uma democracia direta, uma democracia forte no seu sentido mais primitivo, ou seja, do governo da maioria. A avaliação participativa é radical no sentido de ir às raízes, de ser auto-exigente, no que diz respeito aos princípios que a orientam e realizar a educação do julgamento.

Em outros estudos, distinguiram-se algumas aproximações características à AP, como, a sensibilização e negociação política, sua capacidade para tornar-se um instrumento epistemológico para ação política no espaço público, a possibilidade de criar comunidades do bem público, sua condição de exercer-se através da co-gestão e do auto-governo, de produzir-se produzindo e instituindo autonomias $e$ cidadania através de processos permanentes de auto-avaliação e de avaliação descentralizada (LEITE, 2003a; 2003b, 2005).

Uma das características que distingue a avaliação participativa de outras formas de avaliação é a ausência do expert em avaliação, por isto, em princípio, todos podem tomar decisões sobre ela. Sujeitos de diferen- 
tes saberes e posições de poder podem dela apropriar-se. Estes sujeitos protagônicos, através da AP, produzem conhecimento sobre si e suas relações, sobre a instituição e suas relações, um conhecimento social em permanente reconstrução. Ao fazê-lo, realizam uma forma de aprendizagem política de democracia forte. A metodologia da AP envolve discussão, debate e reflexão, uma retórica dialógica permanente sobre o quê fazer, como fazer, como fiscalizar a ação. Os produtos da AP, para além da aprendizagem de democracia forte, sua epistemologia subjetiva, podem ser contabilizados na esfera do ganho de autonomia dos sujeitos e instituições.

\section{Metodologias e sinergias}

A sinergia entre avaliação e tecnologia exige novas habilidades cognitivas e reconfiguração de tarefas e métodos (LANDOW, 1992). À pedagogia compete entender e interpretar novos dispositivos, aprendizagens personalizadas e colaborativas e colocar propostas avaliativas que dêem conta de tempo, lugar e territórios novos em processos micro e macroinstitucionais. Ao pesquisar avaliações e sua qualidade participativa estamos procurando e descobrindo: (a) formas de participação (b) intensidade da participação (c) níveis de controle dos sujeitos sobre as avaliações. A pesquisa avaliativa está sendo realizada por equipe multidisciplinar em vários cenários: universidades (UFRGS, PUC, UFPEL), centros universitários (IPA), uma ONG (AFASO) com parceria internacional (UDELAR).

Trabalhamos com estudos de caso e protocolos de registro. Mini Estudos Etnográficos (KNAPP, 1995) são empregados para captação dos dados que permitam formular os casos. As atividades de avaliação encontradas online e off-line são registradas através de protocolos especialmente preparados para esta investigação. Estes protocolos tanto quanto os casos captados são armazenados em um banco de dados que está disponibilizado on-line e permite acesso e consulta a qualquer pessoa.

Para precisar a terminologia de mini-estudos etnográficos tem-se a dizer que por investigação etnográfica se entende a atividade descritiva de trabalho de campo dos antropólogos culturais e de muitos sociólogos e educadores qualitativos. Entre os elementos básicos da investigação etnográfica figuram: acesso exploratório e aberto a todas as contingências ao problema da investigação; intensa implicação do investigador no entorno social que está sendo estudado como observador e em diferentes graus como participante; o emprego de múltiplas técnicas de investigação intensiva, insistindo na observação participante e nas entrevistas com os informantes-chave; tentativa explícita de compreender os acontecimentos em 
termos de significado que apresentam para aqueles que vivem nesse entorno social; marco interpretativo que sublinhe o importante papel do contexto na determinação da conduta e das inter-relações "estruturais" ou "ecológicas" entre a conduta e os acontecimentos dentro de um sistema funcional; produto de investigação em forma escrita - uma "etnografia" - que interprete os acontecimentos e descreva o entorno com os detalhes suficientemente vivos como para que o leitor "saiba o que é estar ali". (KNAPP, 1995, p. 172).

Para Knapp (1995), os mini-estudos não são assim completos. Eles incluem componentes etnográficos modestos (uma aproximação ao campo em estudo, por exemplo, menor que 120hs), e não chegam a constituir uma ação etnográfica geral e convencional! Mini Estudos Etnográficos constituem uma forma de acesso exploratório a um ambiente; através do envolvimento do investigador com o entorno social. Podem incluir observação, observação participante, entrevistas; recolha de materiais e de dados; compreensão de significados em contexto. Fazem parte dos mini-estudos um marco interpretativo, sugerido na revisão aqui esboçada, e produtos de investigação em forma detalhada e com apoio em fotografia, hipertextos, vídeos ou outros. Vale complementar a posição do autor, que diz: "O trabalho de campo de curto prazo pode resultar particularmente útil na pesquisa da relação entre variáveis às quais a retórica do programa ou o plano de avaliação identificam como importantes." (KNAPP, 1995, p. 192).

Foi desenvolvido um modelo de Protocolo de Registro que abriga as categorias e dados extraídos do resumo das práticas considerados fundamentais para entender cada experiência de avaliação encontrada na literatura acadêmica e na web. Os dados extraídos que constam nestes registros são classificados e diferenciados quanto ao suporte, quanto à modalidade e quanto ao contexto educativo. Cada uma destas classificações compreende subcategorias. A classificação e a diferenciação em cada registro estão pensadas para facilitação da análise das experiências registradas, e, para inclusão e busca em um banco de dados que vem sendo construído especialmente para esta pesquisa com a parceria de estudantes da área de engenharia da produção. Há ainda outros campos que compõem o modelo de protocolo utilizado. Aparece neles a classificação dos registros em contextos online ou off-line, a descrição da fonte de onde o registro foi retirado (livros, periódicos, relatórios, etc.) e sua respectiva referência, o nome do pesquisador responsável pela elaboração do registro e um resumo/descrição do conteúdo contido nas fontes utilizadas. Ver figura 1. 


\begin{tabular}{|c|c|c|}
\hline \multicolumn{3}{|r|}{ IPATIVA ONLINE E OFF-LINE } \\
\hline \multicolumn{3}{|c|}{$\begin{array}{c}\text { Projeto de monitoramento e avaliação do programa de desenvolvimento integrado e } \\
\text { sustentável - DLIS - Manguinhos } \\
\text { ZANCAN, Lenira; BODSTEIN, Regina }\end{array}$} \\
\hline $\mathbf{N}^{\circ}: 010 / \mathrm{AP}$ & $\begin{array}{l}\text { Data: } 12 / 04 / 2005 \\
\text { Pesquisadora: Marieta }\end{array}$ & $\begin{array}{l}\text { Origem da Fonte: Web } \\
\text { Último acesso em: } 12 / 04 / 2005\end{array}$ \\
\hline \multirow{2}{*}{\multicolumn{3}{|c|}{ 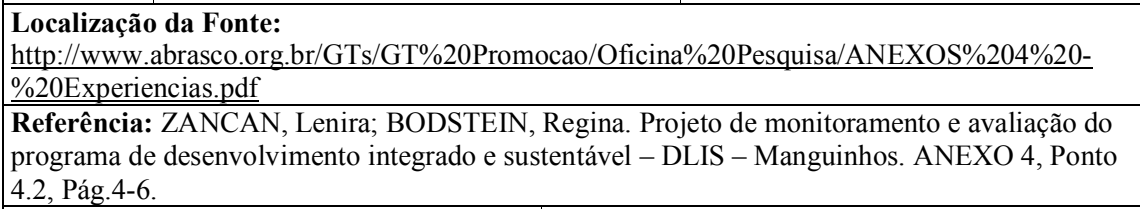 }} \\
\hline & & \\
\hline \multicolumn{2}{|c|}{ Suporte: Educação Presencial } & Modalidade: Avaliação Institucional \\
\hline \multicolumn{3}{|c|}{ Contexto Educativo: Ensino Não-For } \\
\hline \multicolumn{3}{|c|}{ 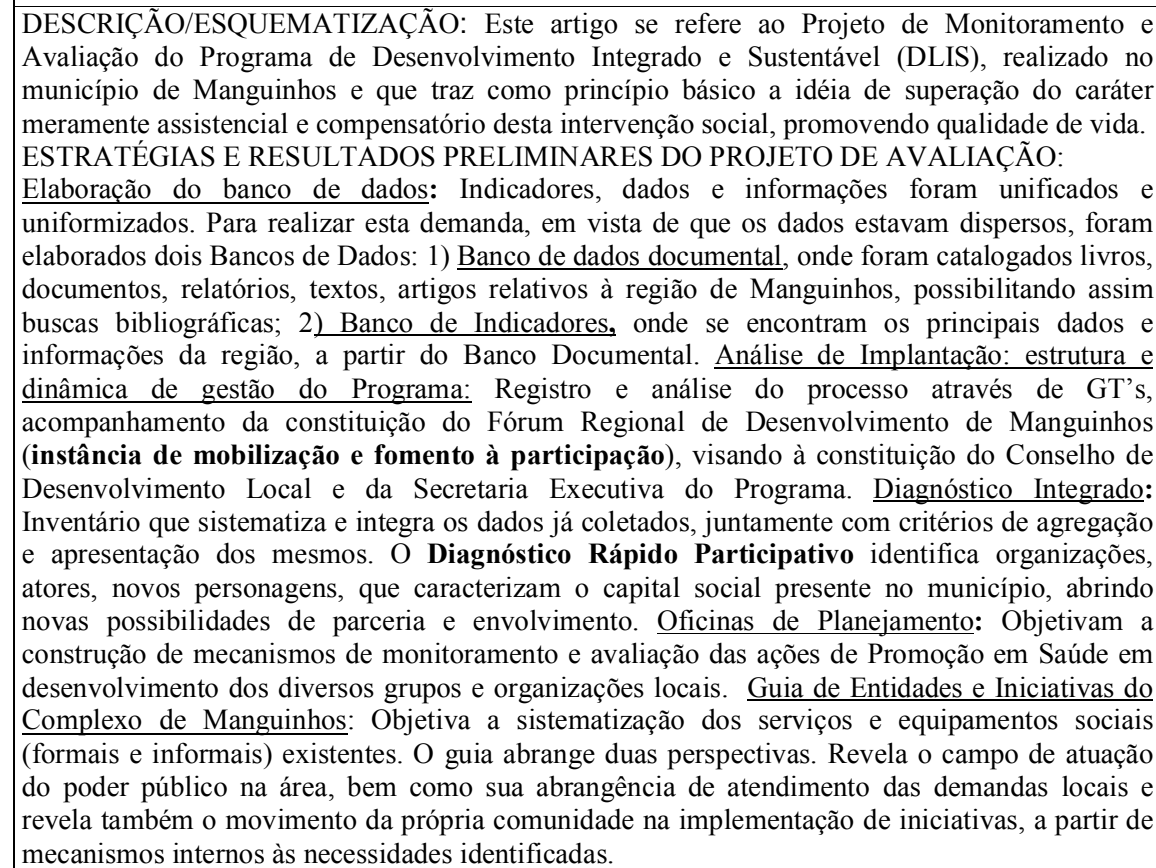 } \\
\hline
\end{tabular}

A análise dos registros obtidos e armazenados em forma de protocolos orienta-se a partir de: a) formas de participação na avaliação; b) intensidade de participação; c) nível de controle dos sujeitos sobre a avaliação. Cada uma destas categorias vem sendo analisada dentro das práticas captadas e classificadas nos protocolos em uma escala de participação com- 
posta por três níveis: baixa ou fraca, moderada ou média e forte. Estas escalas não pretendem ser "duras", ou seja, é possível encontrar e classificar casos em que uma permeie a outra acarretando classificações como: fraca à moderada, moderada à forte. Também não se pretende que os casos estudados sirvam como modelos para outras análises. Ver figura 2.

Figura 2: Exemplo de categorização da participação em protocolos

\begin{tabular}{|c|c|c|c|c|}
\hline \multirow{3}{*}{$\begin{array}{l}\mathbf{P} \\
\mathbf{R} \\
\mathbf{A} \\
\mathbf{T} \\
\mathbf{I} \\
\mathbf{C} \\
\mathbf{A} \\
\text { S }\end{array}$} & & $\begin{array}{l}\text { Nível de } \\
\text { Controle }\end{array}$ & $\begin{array}{l}\text { Formas de } \\
\text { participação }\end{array}$ & $\begin{array}{c}\text { Intensidade da } \\
\text { participação }\end{array}$ \\
\hline & $\begin{array}{c}\text { Planejamento da } \\
\text { Atividade }\end{array}$ & Fraco & $\begin{array}{c}\text { Fraco } \\
\text { (Passiva) }\end{array}$ & $\begin{array}{l}\text { Fraco (Discentes) } \\
\text { Forte (Docentes) }\end{array}$ \\
\hline & Desenvolvimento & $\begin{array}{c}\text { Fraco } \\
\text { (Autonomia } \\
\text { Parcial) }\end{array}$ & $\begin{array}{c}\text { Fraco } \\
\text { (Assistência com } \\
\text { Discussão e } \\
\text { Decisão) }\end{array}$ & $\begin{array}{c}\text { Fraco a Médio } \\
\text { (Poder de decisão ainda } \\
\text { se concentra na figura do } \\
\text { Professor) }\end{array}$ \\
\hline
\end{tabular}

As formas de participação são entendidas tendo em vista distribuição de poder (es) e saber (es) entre sujeitos e tomadas de decisão. Cada formato avaliativo descrito pode agregar outras formas de participação ainda desconhecidas. Estamos permanentemente em alerta para descobri-los, tendo em vista o objetivo da pesquisa de buscar formas de avaliação alternativas e inovadoras voltadas para um processo de formação de sujeitos participativos e democráticos.

\section{RESULTADOS EM ANDAMENTO}

A pesquisa está em andamento. Os primeiros protocolos estão divulgados em página Web preparada para esta finalidade (http://www.ufrgs.br/ inov) e são apresentados em eventos diversos. Dentre os protocolos encontram-se: descrição de formatos AP em currículos, aulas, cursos presenciais e a distância, pesquisados na literatura ou encontrados em sites específicos. Foram elaborados até o momento 38 protocolos na língua portuguesa e 15 protocolos em inglês e espanhol. O protocolo de pesquisa representa um trabalho importante para registrar os estudos em avaliação e entender as práticas que vêm sendo feitas e, com isso, analisar e criar 
categorias que podem dimensionar a avaliação participativa. Seguem-se aos protocolos, os estudos de caso que estão sendo construídos mediante estudo de documentos, observação entrevistas e vêm sendo relatados em eventos pelos pesquisadores e pelos participantes do Grupo de Pesquisa. A página web da pesquisa disponibiliza alguns artigos e estudos realizados por membros do grupo de pesquisa sobre o tema.

Por outro lado, o grupo de pesquisa considera de fundamental importância a discussão de seus trabalhos com públicos diversos. Nessa direção, colaborou e organizou o II Simpósio Nacional de Educação Superior e Desenvolvimento Profissional dias 29 e 30 de junho de 2006, em colaboração com a Rede Sul Brasileira de Investigadores do Ensino Superior RIES, a Coordenadoria das Licenciaturas - COORLICEN e Programa de Pós-Graduação em Educação - PPGEDU/UFRGS. Além disso, os primeiros estudos de protocolos foram apresentados no Salão de Iniciação Científica, em Porto Alegre. Foram apresentados trabalhos na VI ANPED Sul, ENDIPE, Seminário Nacional UNIVERSITAS e II Foro de Innovaciones em Educación, realizado pela CSE/UDELAR. O estudo tem parceria internacional com o Observatório NTIs, UDELAR, Uruguai, e parceria com o Programa Pró-Via/UFRGS. Foi realizado o I WorkShop InovAval com as instituições parceiras.

Em síntese, o esforço da investigação em parceria, a proposta embutida no cerne da concepção, resulta por si só em um aprendizado difícil, porém, constante e revitalizado de democracia forte. Em cada protocolo e em cada caso estudado encontramos alguns indícios de participação. Observamos nos relatos que seus autores, em geral, elogiam o que fizeram em busca da sonhada participação. Teorizam a respeito. No entanto, é restrito o número de estudos encontrados que relatam a experiência de avaliação participativa que realmente aconteceu. Quanto à participação observada nos casos estudados, destaca-se o caso de educação a distância, EAD, no qual a avaliação se efetiva através da autocrítica e autogestão das aprendizagens dos sujeitos com o auxílio das TICs. No espaço institucional encontramos em uma universidade pública o espaço da autoregulação que se fez com uma arquitetura da participação construída ao longo dos anos, reunindo os dados necessários para avaliação de cada unidade de ensino com o esforço de seu centro de processamento e secretaria de avaliação em um projeto de democratização da informação. No espaço de uma ONG encontramos participação no esforço amoroso e solidário dos colaboradores voluntários, estagiários e dirigentes, para bem conduzir as atividades de atendimento às crianças de uma vila periférica. Este tem sido o território do maior número de dúvidas. Torna-se difícil medir o quanto foi gera- 
do em termos participativos cada vez que se estudaram os acontecimentos e se refletiu sobre as propostas e o andamento contigencial de cada atividade realizada e observada.

Desta forma, até o momento, estamos reunindo esforços e procurando entender o quanto os sujeitos que supostamente participam nas avaliações estudadas estariam se aproximando do conceito de democracia forte, do sentido de gestão e de processos educativos conduzidos pela maior parte das pessoas de uma sala de aula, de uma comunidade, de uma instituição. Estamos nos perguntando se, ao "colar" os protocolos e casos estudados aos conceitos teóricos estaríamos "perdendo" a visão de uma qualidade epistemológica nova que ainda não fomos capazes de vislumbrar.

\section{REFERÊNCIAS}

AXT, M.; MARASCHIN, C. Narrativas avaliativas como categoriais autopoiéticas do conhecimento. Revista de Ciências Humanas. Edição especial temática. Florianópolis: UFSC, 1999, p.21-42.

AXT, M. Abrindo espaços de invenção na escola. Porto Alegre: PGIE, CIVITAS, LELIC, UFRGS, 2004. Texto inédito.

BARBER, B. Démocratie forte. Paris: Desclée Brower, 1997.

BERNSTEIN, B. Pedagogía, control simbólico e identidad. Madrid: Morata, 1998.

CASTRO-ALMEIDA, C.; LEBOTERF, G.; NÓVOA, A. A avaliação participativa no decurso de projectos: reflexões a partir de uma experiência em terreno. In: ESTRELA, A.; NÓVOA, A. (Org). Avaliações em educação: novas perspectivas. Porto: Porto Editora, 1993.

COOKE, B.; KOTHARI, U. Participation - the new tyranny. London: Zed Books, 2001.

COUSINS, J.B.; EARL, L. Participatory evaluation in education. Washington: Falmer Press, 1995.

DIAS SOBRINHO, J.; RISTOFF, D. Avaliação democrática. Para uma universidade cidadã. Florianópolis: Insular, 2002.

DILIGENTI, M. Avaliação participativa no ensino superior e profissionalizante. Porto Alegre: Mediação, 2003.

HACK, G.; TAROUCO, L. O processo de avaliação na educação a distância. In: TAROUCO, Liane (Org). Tecnologia digital na educação. Versão Preliminar IV Workshop Informática na Educação. Porto Alegre, PGIE, UFRGS, [s.d].

HOUSE, E. R. 2000. Evaluación, ética y poder. Madrid: Morata, 2000. HOUSE, E.R.; HOWE, K. R. Valores en evaluación y investigación social. Madrid: Morata, 2001. 
KENSKI, V. M. Novas tecnologias. O redimensionamento do espaço e do tempo e os impactos no trabalho docente. Revista Brasileira de Educação, São Paulo, n. 8, p. 58-71, jul./ago. 1998.

KNAPP, M. Contribuciones etnográficas a la investigación evaluativa. In: COOK; REICHARDT (Orgs.). Métodos cualitativos y cuantitativos en investigación evaluativa. Madrid: Morata, 1995.

\section{LANDOW, G. Hipertexto. La convergencia de la teoria crítica} contemporânea com la tecnologia. Barcelona: Paidós, 1992.

LEITE, D. Avaliação e democracia: possibilidades contra-hegemônicas ao redesenho capitalista das universidades. In: MOLLIS, M. Las universidades en América Latina: reformadas o alteradas? Buenos Aires: CLACSO/Asdi, 2003a.

LEITE, D. Institutional evaluation, management practices and the capitalist redesign of universities: a case study. In: AMARAL, Alberto; MEEK, Lynn; LARSEN, Ingvild (Org). The higher education managerial revolution? Dordrecht: Kluwer Academic Press, 2003b.

LEITE, D. Reformas universitárias. Avaliação institucional participativa. Petrópolis: Vozes, 2005.

LITWIN, E. Educação a distância. Temas para o debate de uma nova agenda educativa. Porto Alegre: Artmed, 2001.

LÉVY, P. Educação e cybercultura. A nova relação com o saber. Educação subjetividade e poder. Porto Alegre, n. 5, v.5, p. 9-19, jul. 1998.

LUDKE, Menga, SALLES, Mercedes M. Q. Porto. Avaliação da aprendizagem na educação superior. In: LEITE, Denise B. C., MOROSINI, Marília. (Orgs.). Universidade futurante: produção do ensino e inovação. Campinas: Papirus, 1997.

PETERS, Otto. Didática do ensino a distância. São Leopoldo: Ed. Unisinos, 2001.

SANTOS, B. de S. A universidade do século XXI: para uma reforma progressista da universidade. São Paulo: Cortez, 2004.

SANTOS, B. de S. A reinvenção da emancipação social. Disponível em: <http://www.ces.fe.uc.pt/emancipa/pt/index.html> Acesso em: 18 jun. 2004. SAUL, A. M. Avaliação participante - uma abordagem críticotransformadora. In: RICO, E. M (Org). Avaliação de políticas sociais: uma questão em debate. São Paulo: Cortez, 2001.

SAUL, A. M. Avaliação emancipatória: desafio à teoria e à prática de avaliação e reformulação do currículo. São Paulo: Cortez, 2000.

SILVA, Marcos; SANTOS, Edméa. Avaliação de aprendizagem em educação online. São Paulo: Edições Loyola, 2006.

SÍLVIO, J. La virtualización de la universidad. Caracas: IESALC/ UNESCO, 2000. 